\title{
Rollover stability of precast concrete beams supported by elastomeric bearing pads
}

\section{Estabilidade ao tombamento de vigas pré-moldadas sobre aparelho de apoio de neoprene}
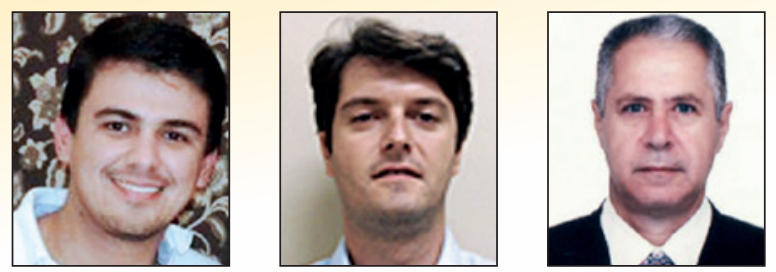

\author{
P. A. KRAHL \\ pablokrahl@usp.br \\ R. CARRAZEDO a \\ carrazedo@sc.usp.br \\ M. K. EL DEBS a \\ mkdebs@sc.usp.br
}

\begin{abstract}
During construction of precast girder bridges, there is the concern on rollover instability of the beams when exclusively supported by elastomeric bearing pads. This type of failure has been the focus of recent research due several accidents reported. However, these studies have not considered the nonlinear behavior of elastomeric bearing pads and the lift-off effect. Therefore, this paper presents a parametric study with a finite element model calibrated with experimental results, reported in the literature, through a nonlinear geometrical analysis and considering that concrete behaves linearly. Besides, the experimental results are compared to simplified approaches which account the pad nonlinear behavior and the lift-off effect by utilizing its secant rotational stiffness. From the results, the difference between the instability load from nonlinear geometrical analysis and experimental results was $8.7 \%$, and the simplified eigenvalue solution and experimental was $11.4 \%$, which was the best fit compared to the other existing analytical models. From the parametrical analysis, the instability load was considerably decreased by varying the initial lateral deflection, the skewed pad rotation, top flange width and the span of the beam.
\end{abstract}

Keywords: precast beam, lift-off effect, bearing pads, rollover instability, nonlinear behavior, numerical analysis, eigenvalue analysis.

\section{Resumo}

Durante a construção de pontes em vigas há a preocupação com a instabilidade por tombamento de vigas quando estão sobre aparelhos de apoio. Este tipo de colapso tem sido foco de pesquisas devido a uma série de acidentes reportados. No entanto, estes estudos não têm considerado o comportamento não-linear dos aparelhos de apoio e a perda de contato entre a viga e o neoprene (lift-off). Portanto, este artigo apresenta um estudo paramétrico com um modelo em elementos finitos, calibrado com resultados experimentais da literatura, através de análise não-linear geométrica. Além disso, os resultados experimentais são comparados com modelos analíticos simplificados que levam em conta o efeito lift-off pela utilização da rigidez secante à rotação do aparelho de apoio. A partir dos resultados, a diferença entre a carga de instabilidade experimental e a obtida pela análise não-linear geométrica foi de $8.7 \%$ e para o modelo de auto-valor simplificado foi $11.4 \%$ que apresentou a melhor aproximação comparado a outros modelos analíticos. Das análises paramétricas, a carga de instabilidade decresceu significativamente pelo aumento do deslocamento lateral inicial, da rotação do aparelho de apoio relativa ao eixo da viga, diminuição da largura da mesa superior da viga e pelo aumento do vão.

Palavras-chave: viga pré-moldada, efeito de lift-off, aparelho de apoio, instabilidade ao tombamento, comportamento não-linear, análise numérica, análise de auto-valor. 


\section{Introduction}

Aligned or skewed precast beams supported by elastomeric bearing pads are frequently applied in bridges due to ease and agility in construction and lower maintenance. Furthermore, the use of high strength materials allows the design of more slender beams, which minimize weight for all stages of construction. However, they become more susceptible to rollover instability when exclusively supported by bearing pads without any lateral bracing, in which the stability of the element is mainly ensured by the rotational stiffness of the bearing pad, [1]-[5].

Structural failures caused by the rollover of precast beams supported by bearing pads are not a new problem in bridge construction. Besides, recently several collapses have been reported. The progressive failure of nine beams with $35 \mathrm{~m}$ of span, as a consequence of rollover instability of one of them, was published by Oesterle et al. [6]. Bairán and Cladera [7] reported the collapse of a $24.9 \mathrm{~m}$ Y-section precast concrete beam during construction of a roof structure. Krahl [4] showed an accident with $45 \mathrm{~m}$ span beams in Brazil when the elements were supported only by bearing pads. In constructions stages of precast bridges, precast beams are partially restrained to rigid body torsional movements. The main transitory situations that these elements are subjected are lifting, transport and when supported only by bearing pads. The first two conditions were widely studied and have consolidated analytical solutions, [1], [8]-[10], as presented in recent research Krahl et al. [11]. However, the last phase is an open field yet, because the difficulty in develops experimental research. Besides, the existing analytical solutions do not predict the few reported experimental results accurately. There is some analytical work done by Flint [12] Lebelle [8] and later by Burgoyne and Stratford [2] that considers the effect of flexible supports on lateral stability of precast beams. The existing experimental researches about this construction phase were performed by Hurff and Kahn [3] and Consolazio [13] that show how critical is this stage when compared to the capacity of the beam in permanent phase. According to these researches, the main concern is the bearing pad behavior and the possibility of loss of contact with the beam (lift-off). Furthermore, the study performed by Consolazio [13] shows that precast beams, when skewed about the bearing pad, presents lower capacity when compared to the aligned case.

To improve the accuracy in safety check of rollover stability of beams, it is essential to account for the nonlinear behavior of the elastomeric bearing pad, including the lift-off effect. Therefore, numerical and analytical studies that incorporate these results could, thus, offer valuable information for the design and construction with precast beams supported by elastomeric bearing pads.

Thus the purpose of this paper is present analytical and numerical studies of rollover stability of precast concrete beams on elastomeric bearing pads. The calibration of the numerical model is based mainly on the experimental results of the precast AASHTO$\mathrm{PCl}$ standard bulb-tee beam tested by Hurff and Kahn [3]. Due to the agreement between the numerical and experimental results, a parametrical analysis is performed that shows the influence of several factors on beam stability as initial imperfections, modulus of elasticity, top flange width, skewed pads and span of the beam. Besides, the presented analytical solutions and the eigenvalue so- lution are further compared to the experimental results of Consolazio [13], for aligned and skewed bearing pads, considering the new approach for the rotational stiffness of the bearing pad.

\section{Analytical solutions}

There exist several ways to determine the critical load of structural members subjected to large displacements. Conventional approaches are Galekin, Rayleigh-Ritz, Runge-Kutta, Finite difference Method and Finite Element Method (FEM). In problems which the supports are flexible to torsional movement, as beams supported only by bearing pads, the critical load is smaller when compared to the situation that the beam is completely restricted to torsion. Some analytical solutions take this effect into account, as in [12], [8] and [2].

Flint [12] determined an adjustment solution by Galerkin approach, for the classical buckling load of beams, with a basis in the differential equation of equilibrium of a displaced beam by adding in the twist rotation function a portion correspondent to rigid body motion. This rigid body rotation corresponds to the movement allowed by the flexible supports. The classical solution for lateral buckling of simply supported beams is presented in equation (1), Timoshenko and Gere [14].

$P_{c r}=\frac{\gamma}{\ell^{2}} A \sqrt{B C}$

Where $B$ and $C$ are the lateral flexural and torsional stiffness, respectively, and $\ell$ is the span of the beam. The coefficient $\gamma$ depends on the load configuration. The cases studied in this paper are beams loaded by a concentrated load at midspan in which $\gamma=16.92$ and beams with third point loads, $\gamma=10.27$. The coefficient $A$ accounts for the effect of the load height with respect to the shear center, according to equation (2).

$A=1-1.74 \frac{a}{\ell} \sqrt{\frac{B}{C}}$

in which $a$ is the distance between the point of load and the shear center.

By considering a possible rotation of the beam at the supports, the adjusted critical load $P_{\text {lim }}$ is related to the support torsional stiffness, as presented in equation (3). This solution is valid for beams with torsional flexible supports at both ends.

$\frac{P_{l i m}}{P_{c r}}=1-\frac{4}{3} \frac{C}{\ell k_{\theta}}$

$k_{\theta}$ is the relation between the applied torque and the resulting twist at the supports or the rotational stiffness of the support. Therefore, $P_{\text {lim }}$ is the adjusted buckling load considering the effect of support flexibility.

Lebelle [8] also developed a solution based on differential equations of equilibrium. The equation accounts for the rotational flexibility of supports and the effect of the position of the applied load, equation (4).

$P_{c r}=k \sqrt{\alpha} \frac{\gamma}{\ell^{2}} \sqrt{B C}$

$k$ and $\alpha$ are constants which depend of concrete and geometrical 
properties. The constant $k$ is obtained through equations (5) to (7).

$k=\sqrt{1+2.47 \beta+0.52 \delta^{2}}-0.72 \delta$

$\beta=\frac{B_{f} 2 z}{C \ell^{2}}$

$\delta=\frac{2 y_{\text {rot }}}{\ell} \sqrt{\frac{B}{C}}$

$B_{f}$ is the lateral flexural rigidity accounting only the inertia of the flanges, $z$ is the distance between the centroids of the flanges and $y_{r o t}$ is the distance between the load application point and the support position. The parameter $\alpha$ is the smaller root of the equation (8).

$\frac{k_{\theta} \ell}{2 C}=\frac{\frac{8}{15} \alpha-\frac{356}{10395} \alpha^{2}}{1-\frac{11}{30} \alpha+\frac{6617}{415800} \alpha^{2}}$

Burgoyne and Stratford [2] proposed an analytical solution for rollover load based on the equilibrium of the beam in a displaced position that is the rollover moment is equilibrated by reaction moment of the bearing pads. The hypothesis of no strain due torsion is accounted. Thus, the beam presents only lateral curvature due flexure. To apply this approach in present paper, the solution was adapted to obtain the concentrated critical load at midspan $P$, but still considering the effect of the self-weight of the beam $w$, equation (9).

$\frac{w^{2} \ell^{5}}{120 B}+w \ell y_{b}-2 k_{\theta}+7 w \ell^{4} P+\frac{5 \ell^{3} P^{2}}{240 B}+P h=0$

The first three parts of left side of equation (9) are exactly the solution of Burgoyne and Stratford [2] considering only self-weight. In the equation, $h$ the height of the beam and $y_{b}$ the distance of center of gravity from the bottom flange.

An eigenvalue problem is performed by solving the equation (10) to determine the critical load through FEM that corresponds a linear analysis of the stability problem.

$\left([K]-\lambda_{\text {crit }}[G]\right)\{\delta\}=\{0\}$

Where $[K]$ is the stiffness matrix, $[G]$ is the stability matrix, $\lambda_{\text {crit }}$ is the smaller real root of the determinant of the terms between parenthesis which corresponds to the eigenvalue and $\{\delta\}$ is the cor- respondent eigenvector. To consider the flexibility of the supports, a torsional spring will be attached at the supports.

Concrete beams present initial imperfections in its geometry. For rollover instability of beams, the initial lateral displacement is the most important. Concrete in curing process commonly presents initial lateral displacements due to shrinkage. There are two possible solutions to take this into account in the stability analysis. The solution of Southwell [15], equation (11).

$\delta_{\text {lim }}=\frac{\delta_{0}}{1-\frac{P_{l i m}}{P_{c r}}}$

And the solution obtained from the precious equation by Massey apud Mandal and Calladine [16], equation (12).

$\delta_{\text {lim }}=\frac{\delta_{0}}{1-\left(\frac{P_{l i m}}{P_{c r}}\right)^{2}}$

This consideration enables to predict analytically the nonlinear load-lateral displacement response of an imperfect beam from which the rollover load can be determined. The critical load is named as limit load $P_{\text {lim }}$ when initial imperfections are accounted. According to Southwell [15] the lateral displacement $\delta_{\text {lim }}$, at a limit load of an imperfect beam, is related to its initial lateral displacement $\delta_{0}$ and the ratio between the limit load and the critical load.

\section{Methodology}

Besides the presented analytical solutions for critical load, a geometrical nonlinear study and an eigenvalue analysis were developed using Finite Element Method (with Abaqus Software release 6.13). The experimental result of the precast AASHTO-PCI standard bulbtee beam (PCI BT-54), experimentally tested by Hurff and Kahn [3], is taken as a reference to compare to the numerical and analytical models. The prestressed beam studied has a height of $137 \mathrm{~cm}, 30.5$ $\mathrm{m}$ of length and is supported by two steel-reinforced rectangular elastomeric pads $(36 \mathrm{~cm} \times 61 \mathrm{~cm})$. The concrete has a modulus of elasticity of $30.8 \mathrm{GPa}$ and Poisson coefficient of 0.22 . A single point load was applied at the midspan in the experiment. This load was kept always vertical and accompanying the beam lateral displacement by utilizing a typical apparatus used in lateral instability studies (gravity load simulator). This instrument does not impose any type of restriction to lateral or torsional movements, Figure 1. More details on the test setup can be found in [3] and [17].

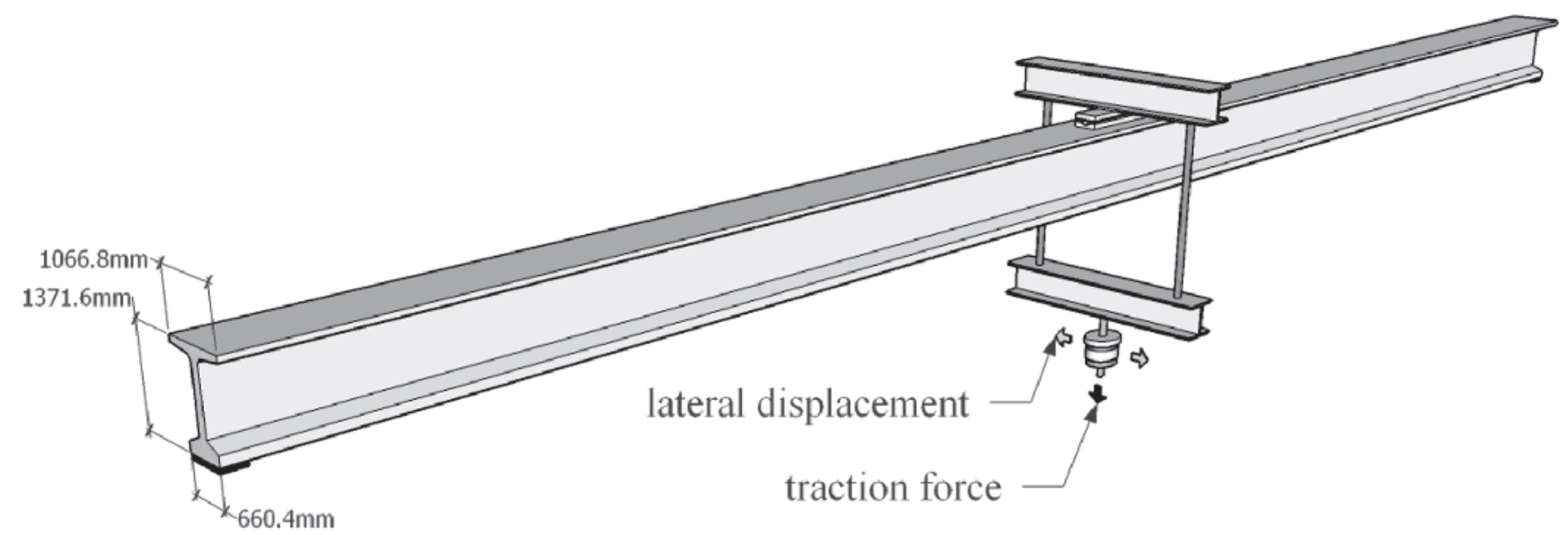

Figure 1

Schematic representation of the beam tested by Hurff and Kahn [3] 


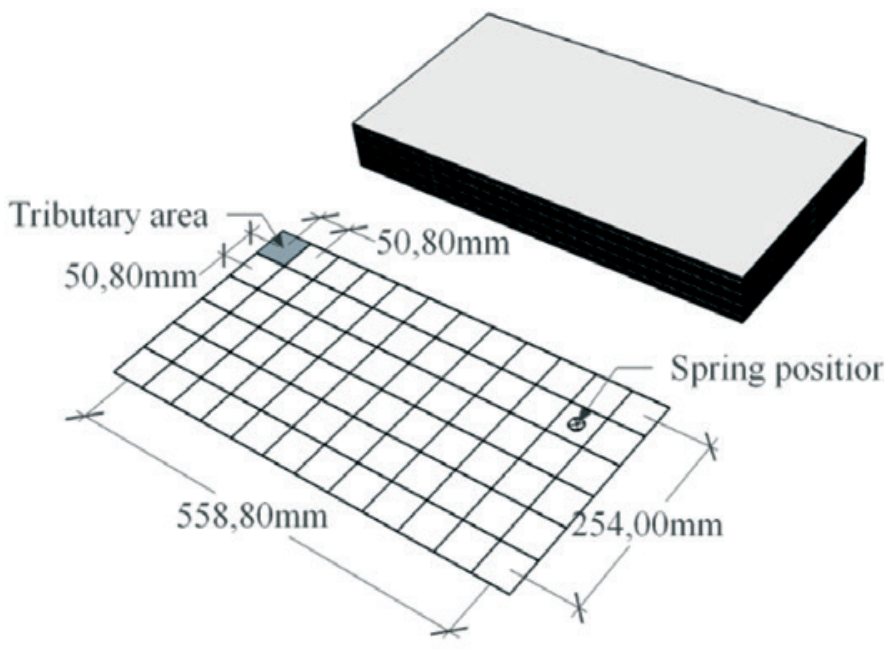

Figure 2

Bearing pad dimensions and numerical model representation

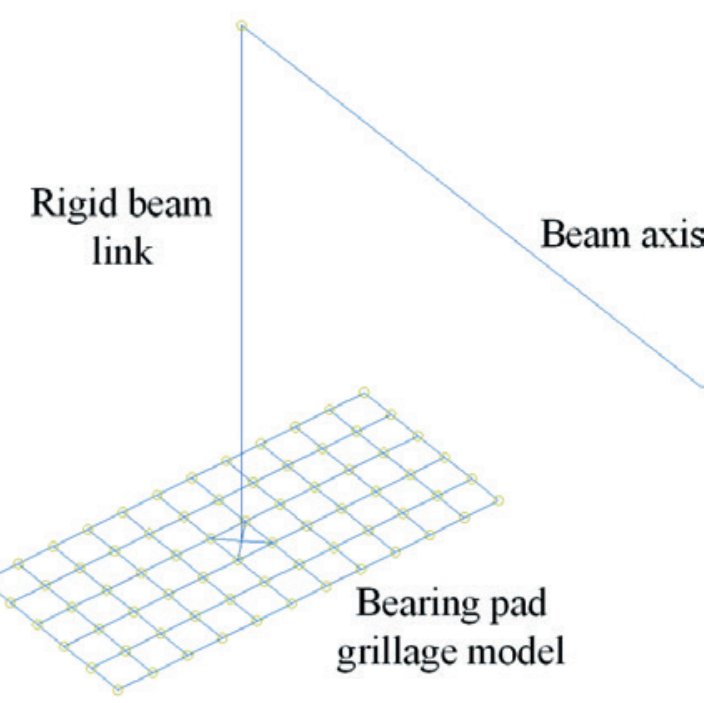

To represent the nonlinear behavior in compression of the bearing pad, a grillage model with nonlinear springs attached at nodes was developed, as in Lee et al. [5]. These springs do not carry tension. Thus, when the beam reaches great twist rotation, the grillage model can account for the loss of contact between the beam and pad (lift-off effect). This model was utilized coupled with numerical beam model to perform the geometrically nonlinear analysis, [5], which enables to obtain the load versus lateral displacement response of the beam and consequently establish a load level at which rollover occurs.

Besides, the grillage model alone enables to determine the secant rotational stiffness of the pad for large rotations correspondent to the rotations of the beam at the time of instability. This secant stiffness is utilized as the stiffness of the torsional springs considered in the analytical calculations and in the numerical eigenvalue analysis. In the eigenvalue analysis, the beam axis is modeled with the same mesh utilized in the geometrically nonlinear analysis. However, instead of the couple the beam to the grillage model, a single torsional spring is attached to the support with the secant rotational stiffness. The eigenvalue problem corresponds to a linear stability analysis.

Since the geometrical nonlinear model was capable of predicting the experimental behavior of the beam PCI BT-54 with accuracy, parametrical studies were carried out in a sensitivity analysis on the effect of skew angle of elastomeric bearing pads, initial lateral sweep, the elastic modulus of concrete, top flange width and span of the beams. These numerical results were compared with analytical calculations and the eigenvalue solution. In the following subsections, more details of methodology are shown.

\subsection{Grillage model of the bearing pads}

The steel reinforced elastomeric bearing pad tested in [3] had five layers of neoprene (thickness of $15 \mathrm{~mm}$ and $7.5 \mathrm{~mm}$, respectively for internal and external layers) and four steel layers $(3.25 \mathrm{~mm}$ of thickness) between them. The horizontal mid-surface of the pad was divided into 72 parts $(50.8 \mathrm{~mm} \times 50.8 \mathrm{~mm})$, and in the center of each region a nonlinear spring was attached receiving the tributary compressive stiffness with no tension stiffness, see Figure 2. As mentioned, this model was used for the geometrically nonlinear analysis and to determine the rotational secant stiffness of the bearing pad to utilize in the analytical solutions and in the eigenvalue analysis. In the geometrical nonlinear analysis, the grillage was linked to the beam longitudinal axis by a rigid beam link, Figure 2. The numerical and experimental compressive load-deflection response of the pad is shown in Figure 3. The experimental curve presented in [3] was the starting point to define the nonlinear compressive stiffness, based on tributary area, of all springs

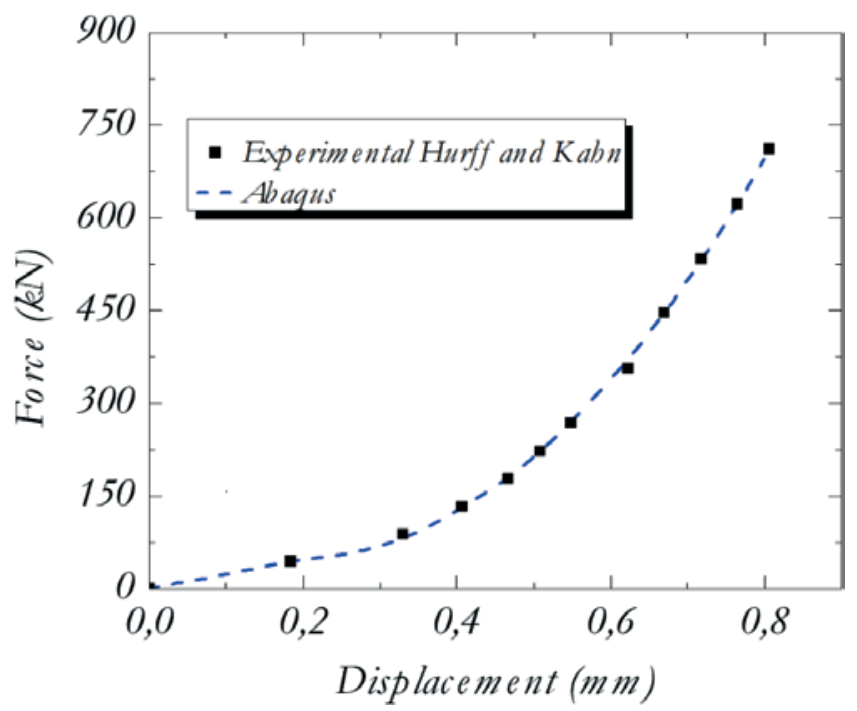

Figure 3

Numerical and experimental axial response of elastomeric bearing pad 
connected to the grillage model. As expected, the compressive load-deflection response of the grillage model represents precisely the experimental curve, as shown in Figure 3.

\subsection{FEM modeling of the precast concrete beam}

The precast beam was discretized with 750 B32OS 3D beam elements along the longitudinal axis, considering symmetry of the model at midspan. This discretization presented low computational cost with good approximation. The finite element utilized is a threenode quadratic beam element with seven degrees of freedom per node which are three translations, three rotations, and warping. Figure 4 shows schematically the mesh and boundary conditions used in the models to perform the geometrically nonlinear analysis. For this study, the grillage model was coupled to the beam, by a rigid link, to represent the nonlinear behavior and the lift-off effect of the bearing pads. A linear elastic behavior was assumed for concrete based on experimental evidence that the beam topples before cracking, as observed by Lima and El Debs[18] and Hurff and Kahn [3]. No steel reinforcement was included in the model. The load application point in midspan was displaced from the shear axis of the beam also by a rigid beam link, Figure 4 .

Due prestressing, the camber suffered by the beam tested by Hurff and Kahn [3] was $110.7 \mathrm{~mm}$ at midspan. In the FEM model, this effect was considered by imposing a sinusoidal shape for the longitudinal beam axis so that the camber at midspan was $110.7 \mathrm{~mm}$ (see the detail in Figure 4).

In instability problems, initial lateral displacement has a significant effect. The strategy was to extract the first mode of an eigenvalue and eigenvector analysis and input this shape as the initial shape of the beam to consider in the nonlinear geometrical analysis. For this eigenvalue analysis, the supports were restricted to rotation about a longitudinal axis and the vertical and lateral displacements. Under these conditions and due to the low lateral rigidity of concrete beams with open cross-sections, the first mode is the beam displaced laterally.

This mode was inputted as the initial shape of the beam, and now the supports are the grillage model to perform the geometrically nonlinear analysis. The maximum initial lateral sweep presented in the PCI BT-54, reported in [3], in the middle of the span was 43.5 $\mathrm{mm}$ which was scaled to the first eigenvector. Therefore, the beam has vertical curvature due prestress and lateral curvature due to initial lateral displacement.

The loading process in numerical analysis consisted in first apply the self-weight of the beam, as actually happens. With this, the pad adjusts its axial nonlinear stiffness. Then, the vertical load at midspan is applied, as in the experimental test showed in Figure 1. The eigenvalue analysis with torsional springs at supports does not consider the effect of initial lateral imperfection. Thus, the Southwell [15] hypothesis and the Massey apud Mandal and Calladine [16] hypothesis are accounted for this effect.

\section{Results and discussion}

\subsection{Response of the grillage model for imposed rotation}

Elastomeric bearing pads present nonlinear behavior when subjected to compressive pressure and with partial loss of contact in its interaction with the beam. Thus, necessary information, as the secant rotational stiffness, is taken from the simulation of the grillage model alone which can take this effects into account. A vertical compressive force is applied correspondent to half of the beam self-weight to obtain the secant stiffness and a rollover movement
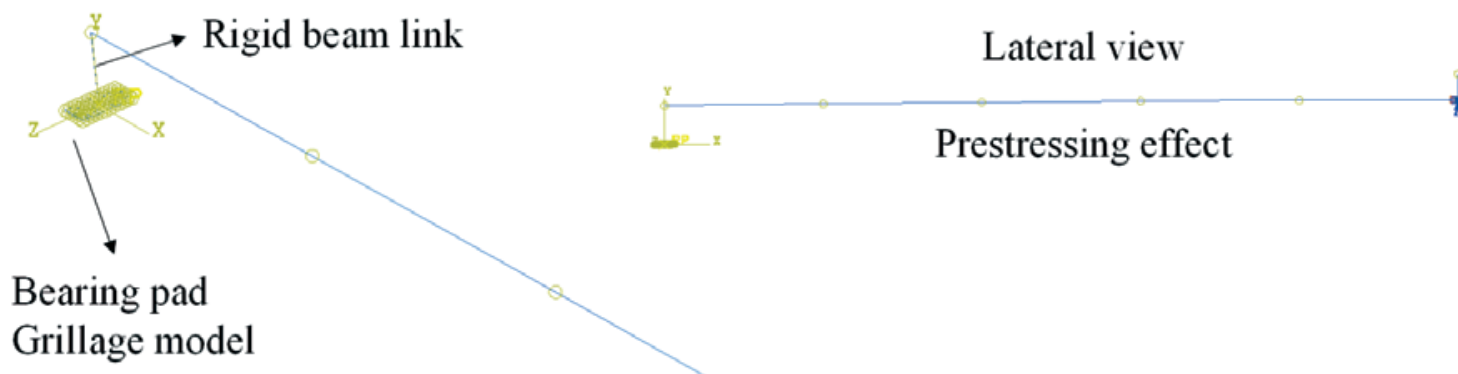

Segments with $3.05 \mathrm{~m}$ and 150 finite elements
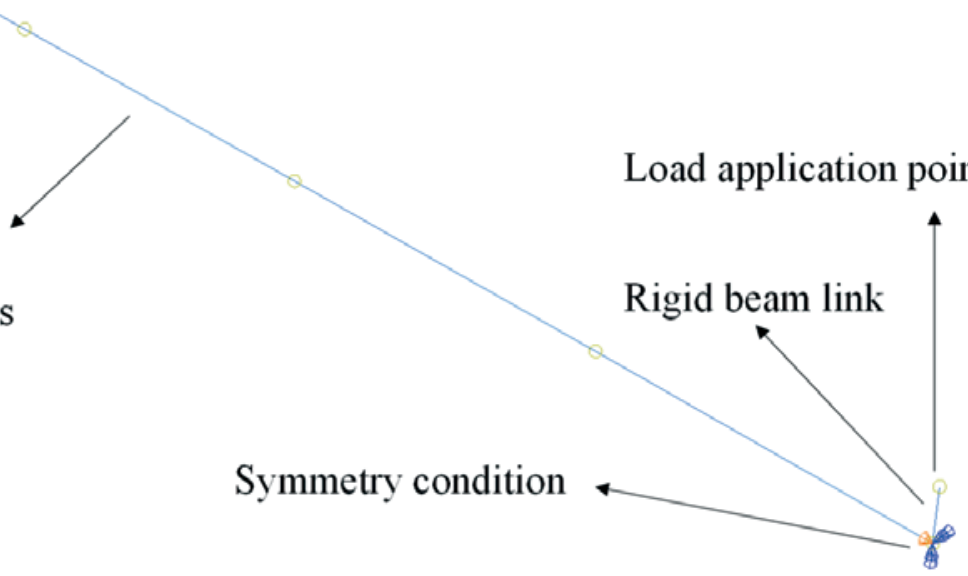

Figure 4

Schematic representation of the numerical model 


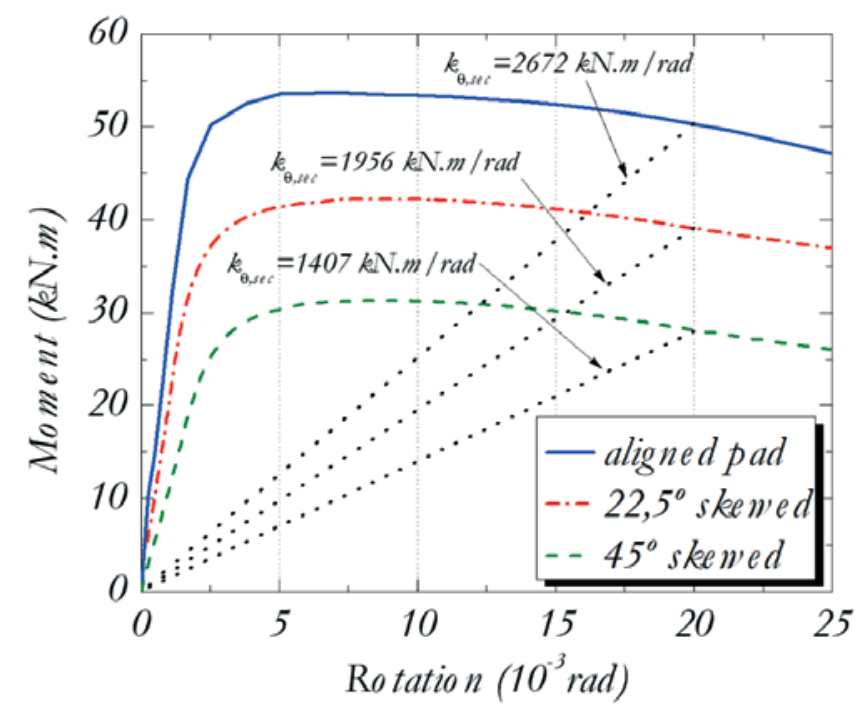

\section{Figure 5}

Numerical moment-rotation response obtained from the grillage model for aligned and skewed pads

due to the beam toppling. Thus, initially, the grillage is axially loaded in steps by a force corresponding to half of the self-weight of the beam PCl BT-54 (162 kN), as occur in construction. Then, a rollover moment correspondent to the direction of the beam axis is applied, also in steps. For the cases of possible skewed angles between pad and beam, the direction of the rollover moment vector takes angles of 22.5 degrees and 45 degrees with the beam longitudinal axis. With this procedure, the nonlinear moment-rotation response is obtained, Figure 5 . In the figure, the secant stiffness for a rotation of 0.02 rad is already presented which corresponds to the beam instability rotation that will be discussed later.

Figure 5 shows that the increase in skew angle decreased the tangent and secant rotational stiffness, by the behavior experimentally observed in [13]. The initial tangent stiffness obtained numerically for the aligned pad was $27490 \mathrm{kN} . \mathrm{m} / \mathrm{rad}$ that is only $10 \%$ greater than the experimental result reported in [3].

As the beam rolls about its longitudinal axis due the applied vertical load and the initial imperfections, the moment in the pad increases until reaches a characteristic plateau, as presented in Figure 5. In this stage, the applied vertical force at the beam midspan cannot increase, but the beam displaces laterally, characterizing rollover instability. From the results presented in Figure 5, the secant rotational stiffness of the bearing pad was highlighted because will be utilized in analytical calculations corresponding to a rotation of $0.020 \mathrm{rad}$.

\subsection{Validation of the numerical model}

The beam PCI BT-54 of $30.5 \mathrm{~m}$ of span tested in laboratory, presented in [3], was considered to validate the numerical model. Figure 6 shows experimental results of applied force at midspan versus midspan rotation compared to the proposed numerical model. The doted and dashed-doted lines correspond to experimental and numerical results of the beam excluding the portion of

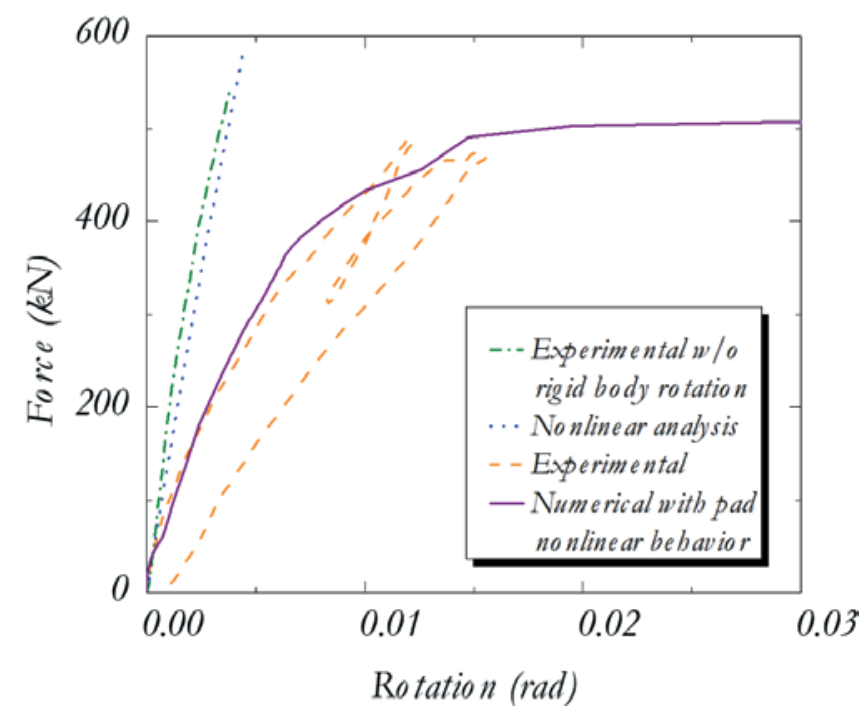

Figure 6

Numerical and experimental load-rotation and load-lateral deflection response of the PCI BT-54

rigid body rotation, respectively. The dashed and solid lines represent respectively the experimental and numerical results of the beam taken into account the behavior of the pad. Figure 7 presents the numerical load versus lateral displacement for PCI BT-54, and in dashed line, the instability load obtained experimentally in [3]. The dashed and dot lines, in Figure 7, corresponds to the results of eigenvalue analysis, considering the torsional springs with the secant stiffness of the bearing pad, combined with the solutions of Southwell [15] and Massey apud Mandal and Calladine [16] to account for initial lateral imperfection.

From the experimental and numerical results in Figure 6, which showed good agreement in load versus rotation response, it can be

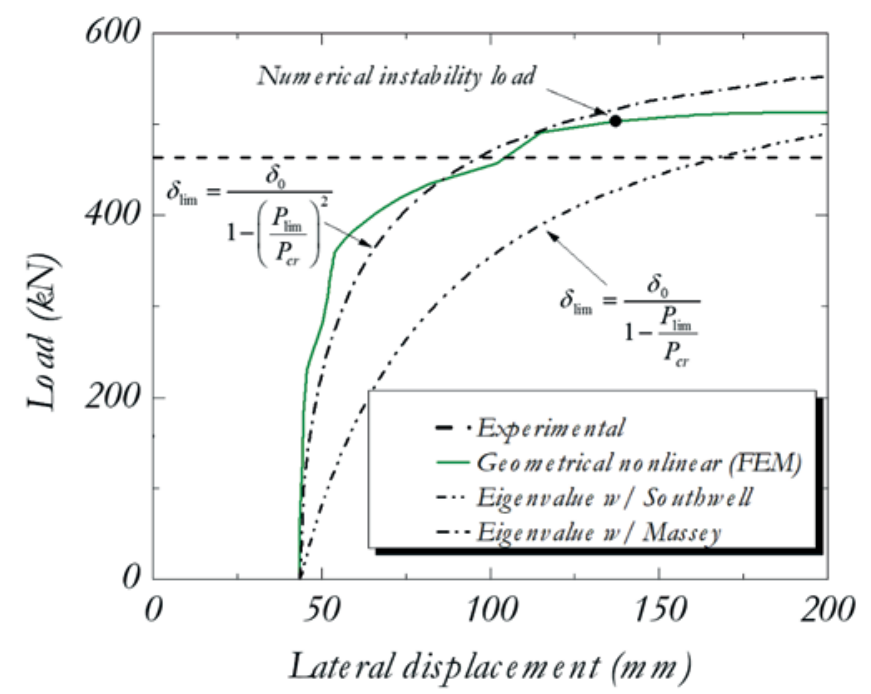

Figure 7

Numerical load-lateral displacement response and the experimental limit load 
Table 1

Comparison of instability load for the beam PCI BT-54

\begin{tabular}{|c|c|c|}
\hline Formulation & Limit load (kN) & Difference (\%) \\
\hline Experimental & 463.0 & 8.7 \\
\hline Geometrical nonlinear analysis & 503.3 & 11.4 \\
\hline Eigenvalue analysis & 516.0 & 267.1 \\
\hline Classical solution & 1699.7 & 26.7 \\
\hline Flint [12] & 586.7 & 258.8 \\
\hline Lebelle [8] & 1661.6 & 136.5 \\
\hline
\end{tabular}

seen that the instability of the beam occurred after the rotation reaches $0.015 \mathrm{rad}$. Hurff and Kahn [3] verified that at a load of $463.0 \mathrm{kN}$ the lateral displacements and rotation of the beam began to increase rapidly with low increase in load, characterizing instability. However, the experiment was stopped due safety reasons which means that the critical rotation could be higher. For this same behavior in the numerical model, for a rotation of 0.02 rad, the beam presents no increase in load. Thus, this rotation was adopted as instability criteria, for which large lateral deflections happen $(13.7 \mathrm{~cm})$, Figure 6 and Figure 7 . In this stage of the load versus rotation curve, the applied load is 503.3 $\mathrm{kN}$ which is considered as the numerical instability load. The difference between experimental instability load and the load obtained from the geometrical nonlinear analysis was $8.7 \%$.

The buckling load obtained from eigenvalue analysis was 626 $\mathrm{kN}$ considering the torsional spring stiffness at supports of 2672 $\mathrm{kN} . \mathrm{m} / \mathrm{rad}$, as presented in Figure 5. Figure 7 shows that with this buckling load combined with Massey apud Mandal and Calladine [16] hypothesis, to consider initial lateral displacement, best fit the geometrically nonlinear analysis curve. The difference in the instability load was $2.5 \%$.

\subsection{Comparison between experimental, numerical and analytical results}

Besides the geometrical nonlinear results and the eigenvalue

\section{Table 2}

Geometrical properties of the beam tested by [13]

\begin{tabular}{|c|c|}
\hline \multicolumn{2}{|c|}{ Beam geometrical properties } \\
\hline Span $(\mathrm{cm})$ & 3050 \\
\hline Height $(\mathrm{cm})$ & 198.12 \\
\hline Area $\left(\mathrm{cm}^{2}\right)$ & 2612.9 \\
\hline Height of centroid $\mathrm{y}_{\mathrm{b}}(\mathrm{cm})$ & 97.51 \\
\hline Moment of inertia $\mathrm{I}_{\mathrm{y}}\left(\mathrm{cm}^{4}\right)$ & 47283.89 \\
\hline Torsion constant J $\left(\mathrm{cm}^{4}\right)$ & 156711.13 \\
\hline Camber due prestress $(\mathrm{cm})$ & 1.75 \\
\hline Initial lateral displacement $(\mathrm{cm})$ & 7.03 \\
\hline Limit lateral displacement $(\mathrm{cm})$ & 16.83 \\
\hline
\end{tabular}

analysis, the analytical solutions of [12], [8], [2] and the classical solution for lateral buckling of beams [14] are evaluated by comparing with the existing experimental results of [3] and [13]. For analytical calculations of the beam PCI BT-54 of [3], the adopted limit displacement was $13.7 \mathrm{~cm}$, and the rotational stiffness of the pad was $2518 \mathrm{kN} . \mathrm{m} / \mathrm{rad}$. Table 1 presents the experimental, numerical and analytical results for the beam PCI BT-54.

For all analytical formulations, the hypothesis of Massey apud Mandal and Calladine [16] was considered. The instability load obtained from geometrical nonlinear analysis best fit the experimental result. However, eigenvalue analysis and Flint [12] solution resulted in good approximation. As expected, all formulations produced instability loads smaller than the classical solution due to the effect of partial torsional restraint at the supports.

The experimental results presented in [13] are also accounted and compared with the analytical solutions and the eigenvalue solution by FEM. The same numerical approach is utilized to determine the

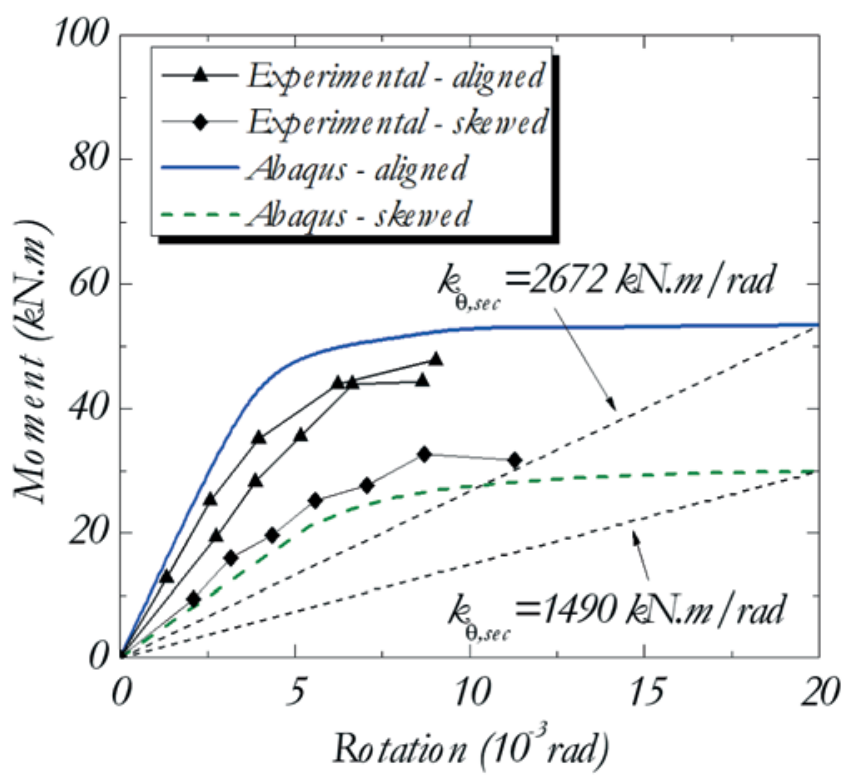

Figure 8

Experimental results of the bearing pad tested in [13] compared to the numerical model of the present study 
Table 3

Comparison of instability load for the beam tested by [13]

\begin{tabular}{|c|c|c|c|c|}
\hline Formulation & Instability load (kN) & Diff. (\%) & Skewed pad (45) & Diff (\%) \\
\hline Experimental & 68.5 & - & 56.9 & - \\
\hline Eigenvalue analysis & 93.6 & 36.6 & 69.9 & 22.8 \\
\hline Classical solution & 312.42 & 356.1 & - & - \\
\hline Flint [12] & 23.6 & 65.5 & No solution & - \\
\hline Lebelle [8] & 178.2 & 160.1 & 143.2 & 152.0 \\
\hline $\begin{array}{c}\text { Burgoyne and } \\
\text { Stratford [2] }\end{array}$ & 129.9 & 89.6 & 75.3 & 32.3 \\
\hline
\end{tabular}

secant rotational stiffness of the bearing pads. Figure 8 presents the numerical results from the grillage model, and experimenta results of [13] for aligned and 45 degrees skewed pads. The pad has plan dimensions of $609.6 \mathrm{~mm}$ per $279.4 \mathrm{~mm}$ with a height of $48.4 \mathrm{~mm}$. There are three steel plates with a thickness of $3.4 \mathrm{~mm}$ between two external $(6.4 \mathrm{~mm})$ and two internal $(12.7 \mathrm{~mm})$ elastomers layers.

The experimental and numerical results had a good agreement. However, the experimental curves stop around $0.01 \mathrm{rad}$, but the secant stiffness is taken at $0.020 \mathrm{rad}$, as previously discussed. The mean modulus of elasticity of concrete utilized by Consolazio [13] is $33.94 \mathrm{GPa}$. The beam geometrical data follow in Table 3 .

With this data and the presented buckling load solutions, the critical instability loads are determined and compared to the experimental results shown in [13] for aligned and skewed pads (45 degrees), given in Table 3. Considering Southwell [15] and Massey apud Mandal and C. R. Calladine [16] hypothesis combined with the eigenvalue solution, the load-lateral displacement response is obtained and compared to the experimental results in Figure 9 and Figure 10

As observed, the eigenvalue result combined with Southwell [15]

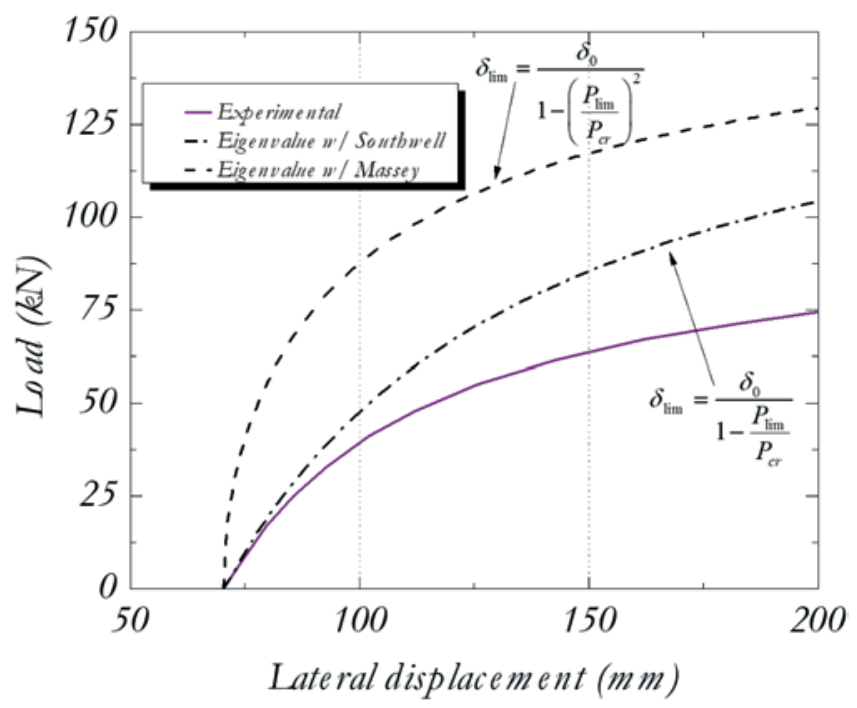

Figure 9

Load-lateral displacement response for aligned pads hypothesis best fit the experimental results for aligned and skewed pads. Thus, the Southwell [15] hypothesis is also considered in the presented analytical solutions, Table 3.

For the beam aligned with the bearing pads, the eigenvalue analysis resulted in the best fit by differing in $36.6 \%$ of the experimental result. When the pads are 45 degrees skewed, the eigenvalue analysis also presented the best fit. Flint [12] do not presented solution when the rotational secant stiffness was $1490 \mathrm{kN} . \mathrm{m} / \mathrm{rad}$ because the factor that adjusts the buckling load in the formulation resulted negative.

\section{Parametrical analysis}

The beam PCI BT-54 was taken as a reference to evaluate the influence of initial imperfections, modulus of elasticity, top flange width, skewed pads and span on beam instability. Besides, the geometrically nonlinear analysis results are taken as reference for comparison with eigenvalue solutions and Flint [12] solution, which presented best fit compared to other analytical solutions. The secant rotational stiffness of the bearing pads are taken into account

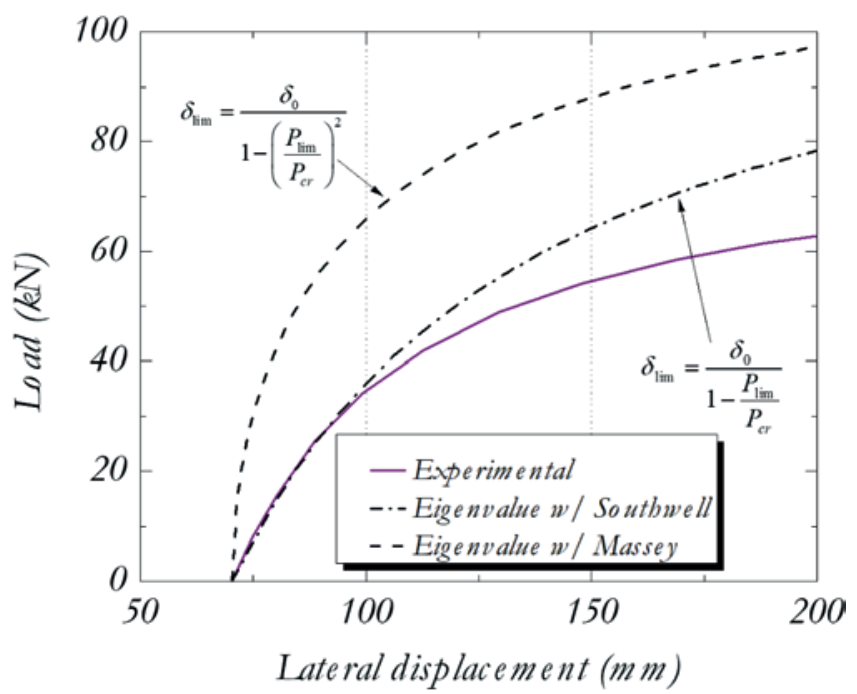

Figure 10

Load-lateral displacement response for 45 degrees skewed pads 
Table 4

Comparison between numerical and analytical solutions of instability load

\begin{tabular}{|c|c|c|c|c|c|c|}
\hline \multirow{2}{*}{ Formulation } & \multicolumn{5}{|c|}{ Initial lateral sweep (mm) } \\
\cline { 2 - 7 } & $\mathbf{4 3 . 5}$ & Diff. (\%) & $\mathbf{6 5}$ & Diff. (\%) & 95 & Diff. (\%) \\
\hline $\begin{array}{c}\text { Geometrical } \\
\text { nonlinear }\end{array}$ & 503.3 & - & 407.1 & - & 382.2 & - \\
\hline Eigenvalue & 516.0 & 2.5 & 470.4 & 15.5 & 407.0 & 6.5 \\
\hline Flint [12] & 586.7 & 16.6 & 534.4 & 31.3 & 471.5 & 42.8 \\
\hline
\end{tabular}

for this two last solutions and the Massey apud Mandal and Calladine [16] hypothesis to consider initial lateral displacement.

\subsection{Lateral initial sweep variation}

The initial lateral sweep of $65 \mathrm{~mm}$ and $95 \mathrm{~mm}$ are simulated with the numerical and analytical models, taking the results of Figure 7 as a reference. The material parameters of the beam presented in [3] are considered. Figure 11 gives the numerical results for force-midspan rotation considering geometrical nonlinear effects. Figure 12 shows the numerical load-lateral displacement response and analytical solutions obtained from the combination of eigenvalue analysis and Massey apud Mandal and Calladine [16] hypothesis. For a rotation of $0.02 \mathrm{rad}$, the lateral displacements at instability load are $150 \mathrm{~mm}$ for initial lateral sweep $65 \mathrm{~mm}$ and $170 \mathrm{~mm}$ for an initial sweep of $95 \mathrm{~mm}$. For the same rotation of $0.02 \mathrm{rad}$, the decrease in instability load in the geometrically nonlinear analysis was $19.1 \%$ when the initial lateral displacement increases from $43.5 \mathrm{~mm}$ to $65 \mathrm{~mm}$ and decreased $24.1 \%$ when the initial lateral displacement increases from $43.5 \mathrm{~mm}$ to $95 \mathrm{~mm}$. Table 4 presents the comparison between the instability load obtained from the geometrically nonlinear analysis, eigenvalue analysis, and Flint [12] solution.

For the mentioned displacements at instability, the eigenvalue

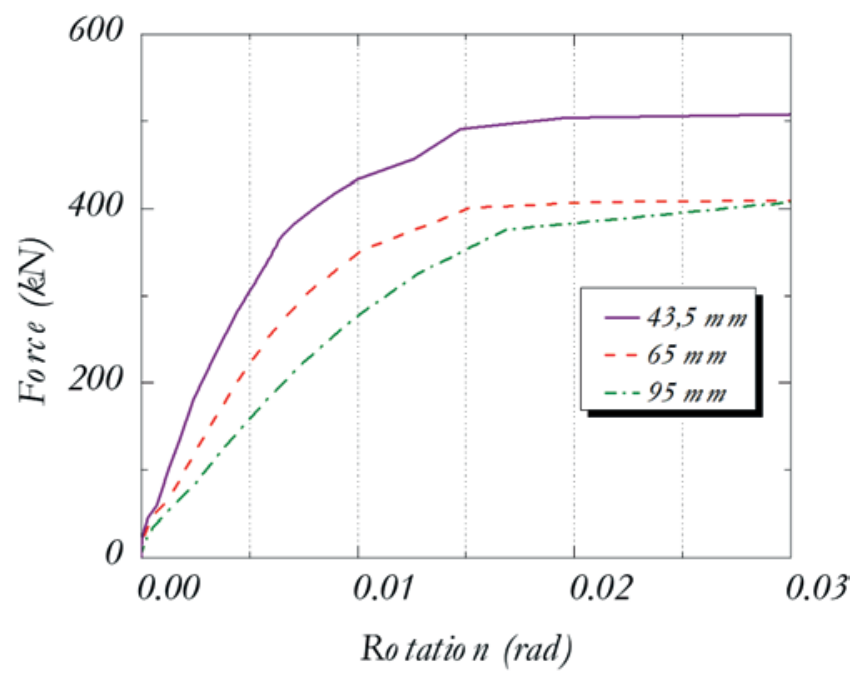

Figure 11

Load-rotation response from geometrical nonlinear analysis results in the best fit of the geometrical nonlinear results.

\subsection{Pad rotation}

Bridges constructed with precast beams can have the pads skewed to the beam longitudinal axis. For the PCI BT-54, the skewed situations of 22.5 degrees and 45 degrees for the pad are simulated and compared to the aligned case. Figure 13 presents the results of nonlinear geometrical analysis of load applied at midspan versus rotation at the same point. Figure 14 shows the load-lateral displacement response from geometrical nonlinear analysis and eigenvalue analysis considering Massey apud Mandal and Calladine [16] hypothesis for imperfections.

The instability load is considerably reduced when the pad was skewed relative to beam axis in the nonlinear analysis. For 22.5 degrees, the reduction was $31 \%$ compared to the aligned beam, and for 45 degrees, the decrease was $46.7 \%$.

Table 5 presents the comparison between instability load of analytical results of Flint [12], eigenvalue analysis and geometrically nonlinear analysis. Besides, the differences concerning the geometrical nonlinear analysis results are presented.

For pads skewed 22.5 degrees, the best fit was obtained by Flint [12] solution. For pads skewed 45 degrees, the best fit was the

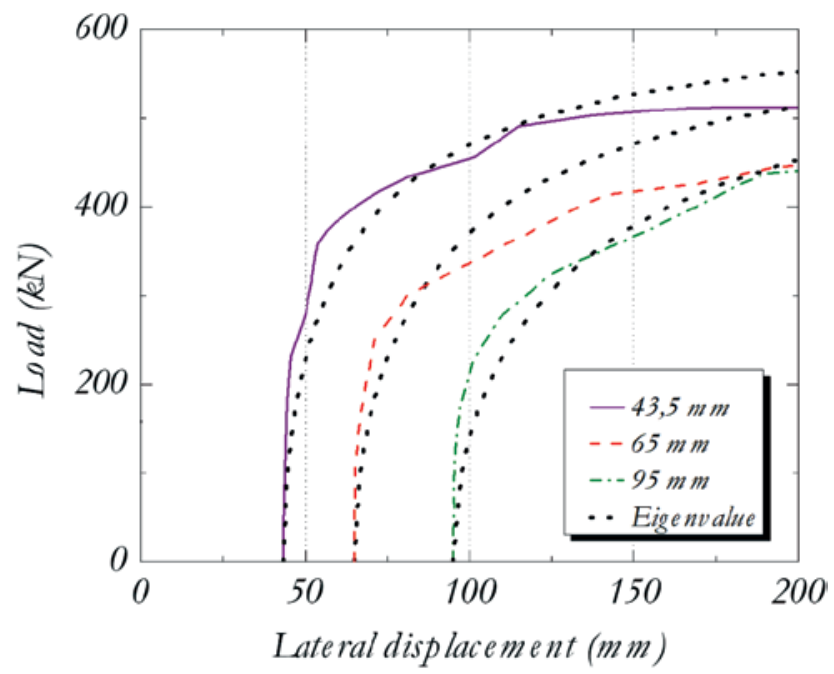

Figure 12

Numerical and analytical load-lateral displacement response 


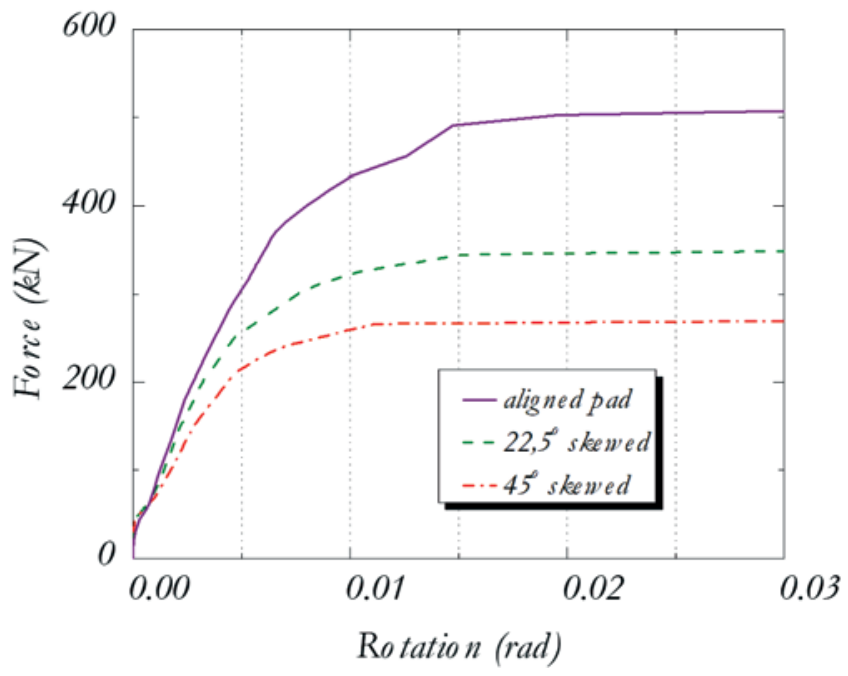

Figure 13

Load-rotation response for aligned and skewed pads

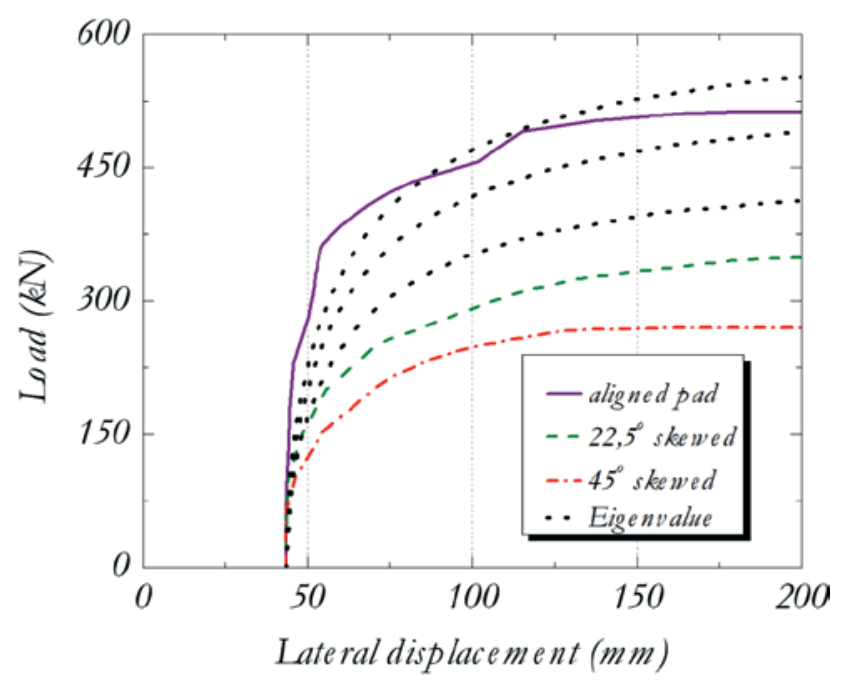

Figure 14

Load-lateral displacement response

\section{Table 5}

Comparison between numerical and analytical solutions

\begin{tabular}{|c|c|c|c|c|c|c|}
\hline \multirow{2}{*}{ Formulation } & $\begin{array}{c}\text { Aligned } \\
(\mathrm{kN})\end{array}$ & $\begin{array}{c}\text { Difference } \\
(\%)\end{array}$ & \multicolumn{4}{|c|}{ Skewed pad (kN) } \\
\cline { 4 - 7 } & & $\mathbf{2 2 . 5 ^ { \circ }}$ & Diff. (\%) & $\mathbf{4 5}^{\circ}$ & Diff. (\%) \\
\hline $\begin{array}{c}\text { Geometrical } \\
\text { nonlinear }\end{array}$ & 503.3 & - & 347.0 & - & 268.0 & - \\
\hline Eigenvalue & 516.0 & 2.5 & 458.9 & 32.2 & 386.6 & 44.3 \\
\hline Flint [12] & 586.7 & 16.6 & 266.6 & 23.1 & No solution \\
\hline
\end{tabular}

eigenvalue analysis, because no solution was obtained by Flint [12] equation.

\subsection{Modulus of elasticity variation}

The beam tested by Hurff and Kahn [3] has the modulus of elasticity of $30.8 \mathrm{GPa}$ which is taken as reference. Two more cases are considered to evaluate the influence of this parameter on the stability behavior of the beam tested by the authors, $40 \mathrm{GPa}$ and $50 \mathrm{GPa}$. Figure 15 presents the results of nonlinear geometrical analysis and Figure 16 the load-lateral displacement of nonlinear geometrical analysis and the eigenvalue analysis. The main influence of the modulus of elasticity in the geometrically nonlinear analysis was in the initial range of the force versus rotation curve. However, the instability load increases little compared to the reference case. The increase in modulus of elasticity from $30.8 \mathrm{GPa}$ to $40 \mathrm{GPa}$ had little improvement in the instability load. Relative to $50 \mathrm{GPa}$, the increase was 7.6 $\%$. Table 5 presents the comparison of nonlinear geometrical analysis to the eigenvalue analysis and the analytical solution of Flint [12].

The eigenvalue solutions presented best fit to the instability load obtained from the nonlinear geometrical analysis. The parameter $\frac{4}{3} \frac{\mathrm{C}}{\mathrm{lk}_{\theta}}$ that adjusts the instability load in Flint [12] solution decreases with increase in modulus of elasticity. For $50 \mathrm{GPa}$, the parameter results negative which has no physical meaning.

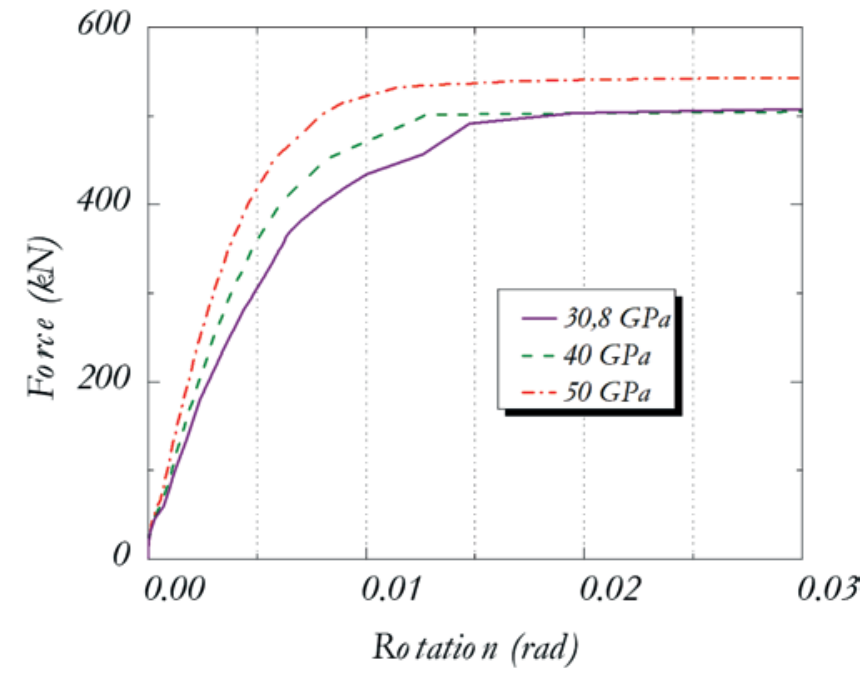

Figure 15

Load-rotation response for modulus of elasticity variation 


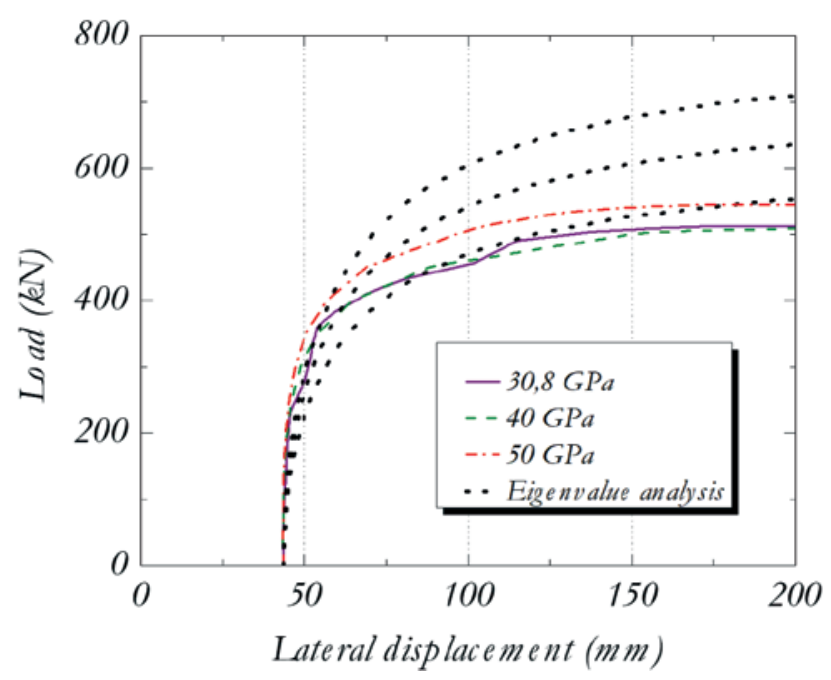

Figure 16

Load-lateral displacement response

\subsection{Top flange width variation}

In some beam bridges, the beams have no top flange in construction stages, as the SY series of precast beams fabricated in the United Kingdom, Stratford et al. [9]. The PCI BT-54 is taken as a reference, to evaluate the top flange influence on lateral stability behavior and the top flange is reduced until reaches the web width. The flange widths considered are $106.7 \mathrm{~cm}, 61 \mathrm{~cm}$, and $15.2 \mathrm{~cm}$. Figure 17 presents the results of the nonlinear geometrical analysis. The rotation of 0.02 rad is deemed to be critical for lateral stability. Figure 18 shows the comparison of load-lateral displacement response from geometrical nonlinear analysis and the eigenvalue analysis.

The decrease in top flange width reduces the load of instability. In the geometrical nonlinear analysis results, for the flange width of $61 \mathrm{~cm}$ the reduction in instability load was $22.7 \%$ compared to the reference

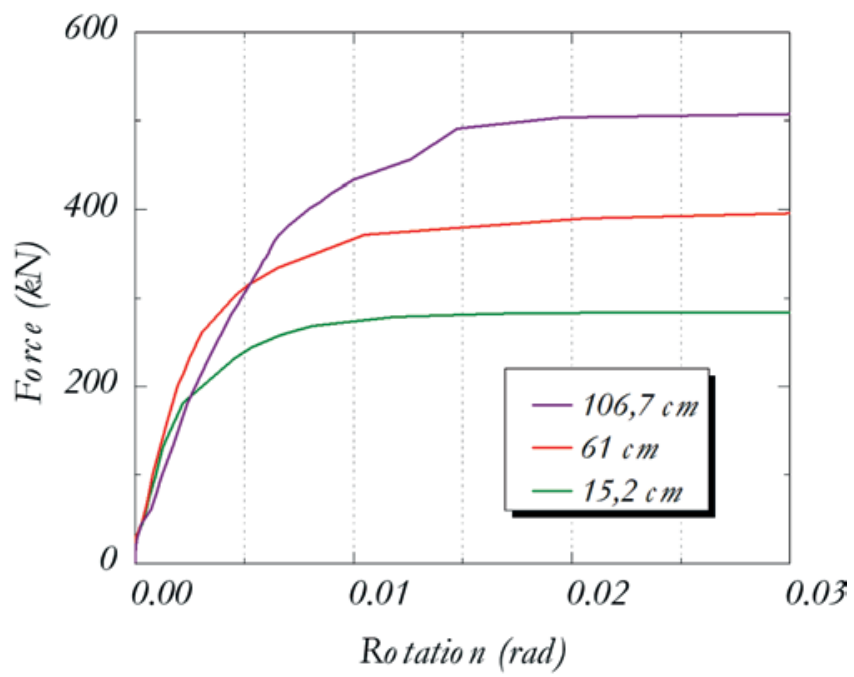

Figure 17

Load-rotation response for top flange variation case, and for the beam with no top flange, the decrease was $44.1 \%$. Table 7 presents the comparison of nonlinear geometrical analysis to the eigenvalue analysis and the analytical solution of Flint [12]. The eigenvalue results presented the best fit to the geometrical nonlinear analysis.

\subsection{Span variation}

$\mathrm{PCl}$ BT-72 is another type of PCl bulb-tee beam which is commonly used for large spans. This beam was taken with a span of $41.45 \mathrm{~m}$ to compare to the lateral stability behavior to the $\mathrm{PCl}$ BT-54 presented in [3]. Camber and lateral imperfections for $\mathrm{PCl}$ BT-72 are taken proportional to the values reported for PCI BT-54 that are $150.4 \mathrm{~mm}$ and $59.1 \mathrm{~mm}$, respectively. Figure 19 and Figure 20 present the comparison of results. The limit displacement for PCl BT-72 adopted is $210 \mathrm{~mm}$, according to the geometrical nonlinear analysis.

The instability load obtained from the geometrically nonlinear analysis for the PCI BT-72 is $391.9 \mathrm{kN}$ whose difference is $13.7 \%$ for the reference case. As the displacements at instability are different, its valuable compare the load carrying capacity for a same large lateral displacement, as $150 \mathrm{~mm}$. For this case, the difference between the considered cases is $22.8 \%$. Table 8 presents the comparison of geometrical nonlinear analysis to the eigenvalue analysis and the analytical solution of Flint [12].

The eigenvalue solution presented the best fit compared to the instability load obtained from the geometrical nonlinear analysis.

\section{Conclusions}

From the numerical and analytical studies of the lateral stability of precast beams supported by elastomeric bearing pads, the main findings are:

a) The consideration of the geometrical nonlinear effects to simulate the stability of beams supported by elastomeric bearing pads presented good approximation of the experimental load

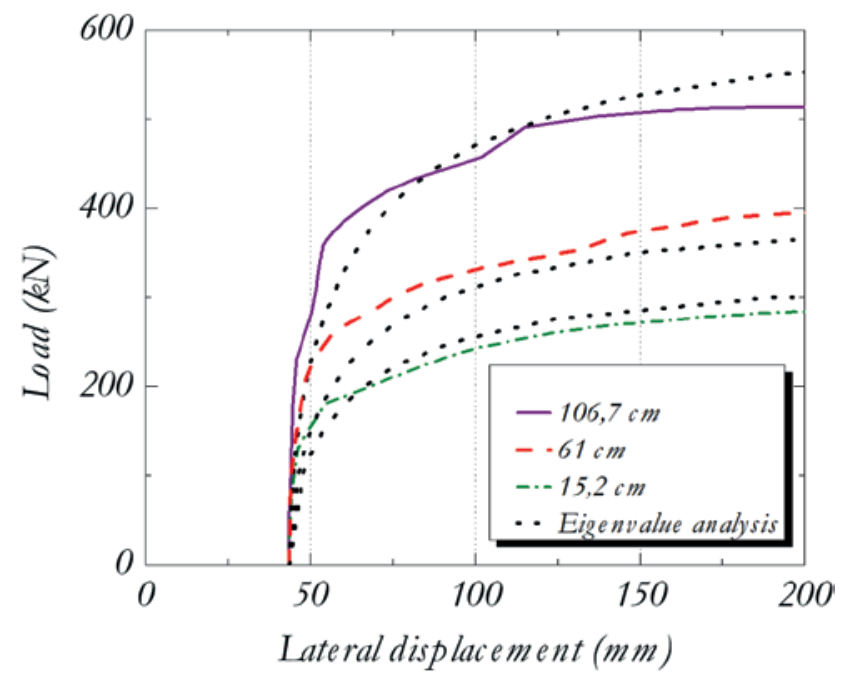

Figure 18

Load-lateral displacement response 
Table 7

Comparison between numerical and analytical solutions of instability load

\begin{tabular}{|c|c|c|c|c|c|c|}
\hline \multirow{2}{*}{ Formulation } & \multicolumn{7}{|c|}{ Top flange width (cm) } \\
\cline { 2 - 7 } & $\mathbf{1 0 6 . 7}$ & Diff. (\%) & $\mathbf{6 1}$ & Diff. (\%) & $\mathbf{1 5 . 2}$ & Diff. (\%) \\
\hline $\begin{array}{c}\text { Geometrical } \\
\text { nonlinear }\end{array}$ & 503.3 & - & 359.0 & - & 266.8 & - \\
\hline Eigenvalue & 516.0 & 2.5 & 341.2 & 5.0 & 280.2 & 5.0 \\
\hline Flint [12] & 586.7 & 16.6 & 450.0 & 25.3 & 403.2 & 51.1 \\
\hline
\end{tabular}

Table 8

Comparison between numerical and analytical solutions of instability load

\begin{tabular}{|c|c|c|c|c|}
\hline Formulation & BT-54 & Diff. (\%) & BT-72 & Diff. (\%) \\
\hline Geometrical nonlinear & 503.3 & - & 413.8 & - \\
\hline Eigenvalue & 516.0 & 2.5 & 342.6 & 17.2 \\
\hline Flint [12] & 586.7 & 16.6 & 492.8 & 19.1 \\
\hline
\end{tabular}

versus midspan rotation response of the beam PCI BT-54 tested by Hurff and Kahn [3]. The difference between numerical and experimental instability loads was $8.7 \%$ which was the best fit compared to the other utilized solutions.

b) From the simplified analyses, which considers the secant rotational stiffness of the bearing pad, the eigenvalue solution presented the best fit of the load versus lateral displacement curve obtained from the geometrically nonlinear analysis. For the displacement that corresponds to instability, the difference in the instability load was $2.5 \%$. The hypothesis of Massey apud Mandal and C. R. Calladine [16] was utilized to account initial lateral displacements.

c) For the others solutions presented to obtain the buckling load, Flint [12] equation showed the best fit compared to the experimental result given in [3]. The difference was $26.7 \%$. The other

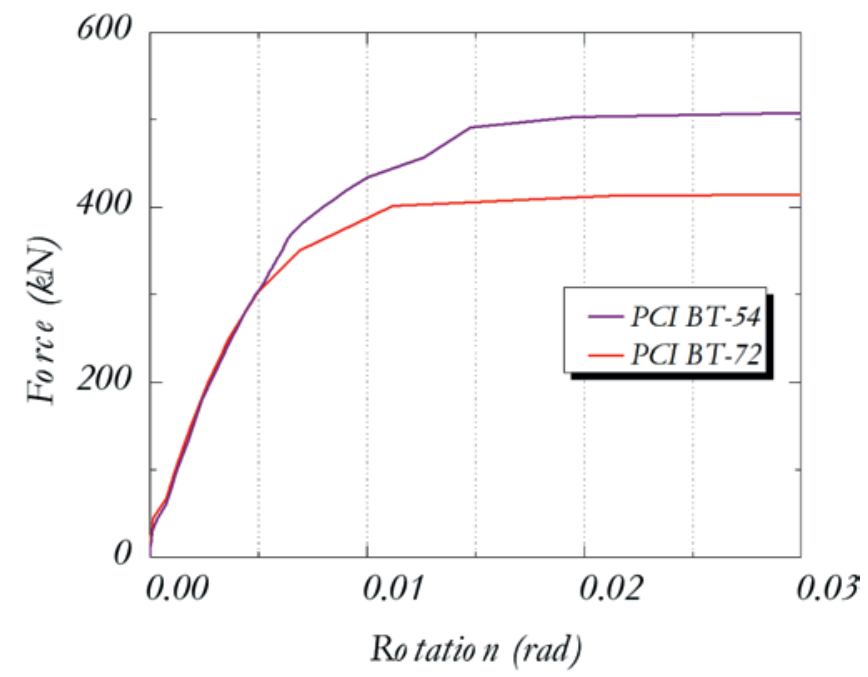

Figure 19

Load-rotation response solutions considerably overestimate the instability load.

d) From the comparison of the simplified solutions with the experimental results presented by Consolazio [13], the best fit was obtained for the eigenvalues analysis. The differences for aligned and 45 degrees skewed pads was $36.6 \%$ and $22.8 \%$, respectively. Besides, the Southwell [15] hypothesis was considered to account initial lateral displacements.

e) The increase in lateral imperfection has a significant effect on beam lateral stability. For the rotation of 0.02 rad which is considered as critical, the difference in instability load between the reference case, which has initial imperfection of $43.5 \mathrm{~mm}$, and the further cases, which have $65 \mathrm{~mm}$ and $95 \mathrm{~mm}$, were $19.1 \%$ and $24.1 \%$, respectively.

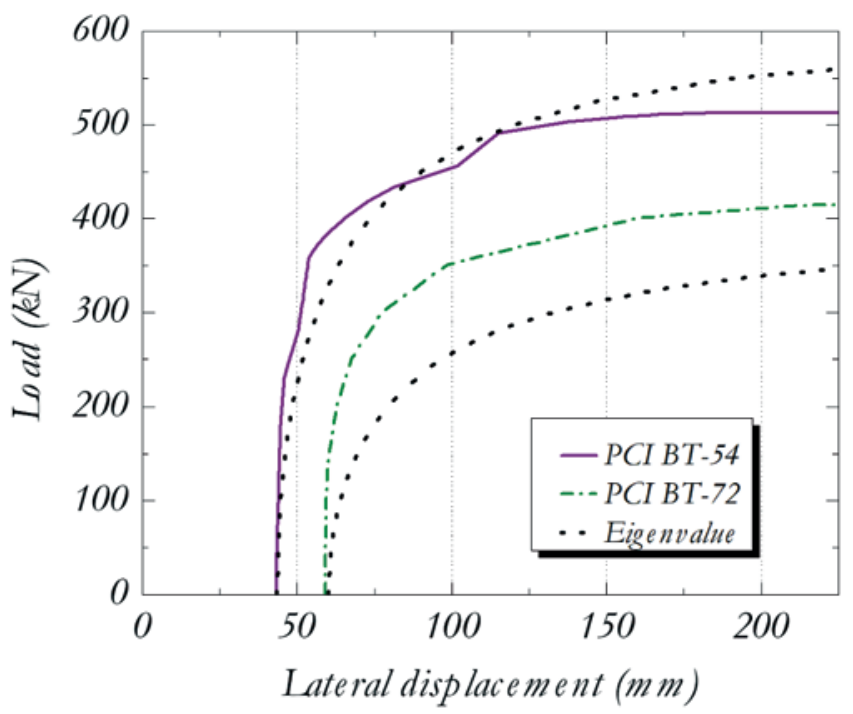

Figure 20

Numerical and analytical load-lateral displacement response 
f) The variation of modulus of elasticity has a small influence in the geometrically nonlinear analysis of the beam PCI BT-54. The maximum change in the limit load of the numerical model was $7.6 \%$ among the cases of $30.8 \mathrm{GPa}$ and $50 \mathrm{GPa}$. The comparison between the instability load obtained from the geometrically nonlinear analysis and eigenvalue solution resulted in differences of $18.2 \%$ and $22.5 \%$ for the cases of $40 \mathrm{GPa}$ and $50 \mathrm{GPa}$.

g) For pad rotation concerning the beam axis in the geometric nonlinear analysis, the instability load of the aligned pad is $31 \%$ greater than the case with the pad skewed 22.5 degrees and $46.7 \%$ greater than the pad 45 degrees skewed. For pads 22.5 degrees skewed, the Flint [12] was the best fit with a difference of $23.1 \%$ compared to the instability load obtained from the geometrically nonlinear analysis. For 45 degrees, the eigenvalue solution presented the best fit, with a deviation of $44.3 \%$.

h) The reduction in the top flange width has high impact in the instability limit load. For the further cases of the top flange with 62 $\mathrm{cm}$ and $15.2 \mathrm{~cm}$, the decrease in limit load was $22.7 \%$ and 44.1 $\%$, respectively. The eigenvalue solution presented the best fit to the geometrical nonlinear result with differences $5.0 \%$ for the further cases.

i) For a lateral displacement of $150 \mathrm{~mm}$ in the geometrically nonlinear analysis, the difference between the load carrying capacity of the beams PCI BT-54 and PCI BT-72 is $22.8 \%$. The best fit for the instability load of the PCI BT-72, resulted from the nonlinear analysis, was obtained by the eigenvalue solution whose difference was $17.2 \%$.

j) There is the necessity of further experimental researches in this field given the few existing ones. Besides, the development of new analytical solutions that better predicts the instability load of the beams in this construction situations.

\section{Acknowledgements}

Authors gratefully acknowledge the funding provided by $\mathrm{CNPq}$ (National Counsel of Technological and Scientific Development).

\section{References}

[1] R. F. Mast, "Lateral stability of long prestressed concrete beams, part 1," PCI J., vol. 34, pp. 34-53, 1989.

[2] C. J. Burgoyne and T. J. Stratford, "Lateral instability of longspan prestressed concrete beams on flexible bearings," Struct. Eng., vol. 79, pp. 23-26, 2001.

[3] J. B. Hurff and L. F. Kahn, "Rollover stability of precast, prestressed concrete bridge girders with flexible bearings," $\mathrm{PCl}$ J., pp. 96-107, 2012.

[4] P. A. Krahl, "Instabilidade lateral de vigas pré-moldadas em situações transitórias," Escola de Engenharia de São Carlos - USP, 2014

[5] J. Lee, I. Kalkan, J. Lee, and J.-H. Cheung, "Rollover instability of precast girders subjected to wind load," Mag. Concr. Res., vol. 69, no. 2, pp. 68-83, 2017.

[6] R. G. Oesterle, M. J. Sheehan, H. R. Lotfi, W. G. Corley, and J. J. Roller, "Investigation of Red Mountain Freeway Bridge Girder Collapse," 2007.
[7] J. M. Bairán and A. Cladera, "Collapse of a precast concrete beam for a light roof. Importance of elastomeric bearing pads in the element's stability," Eng. Fail. Anal., vol. 39, pp. 188-199, 2014.

[8] P. Lebelle, "Stabilité élastique des poutres en béton précontraint a l'égard de déversement latéral," Ann. Batim. des Trav. Publics, vol. 141, pp. 780-830, 1959.

[9] T. J. Stratford, C. J. Burgoyne, and H. P. J. Taylor, "Stability design of long precast concrete beams," in Proceedings of the Institution of Civil Engineers - Structures and Bridges, 1999, pp. 159-168.

[10] T. J. Stratford and C. J. Burgoyne, "Lateral stability of long precast concrete beams," in Proceedings of the Institution of Civil Engineers - Structures and Bridges, 1999, vol. 124, pp. 169-180.

[11] P. A. Krahl, M. C. V. Lima, and K. M. El Debs, "Recommendations for verifying lateral stability of precast beams in transitory phases," IBRACON Struct. Mater. J., pp. 1-20, 2015.

[12] A. R. Flint, "The Influence of Restraints on the Stability of Beams," Struct. Eng., pp. 235-246, 1951.

[13] G. R. Consolazio, "Experimental Validation Of Bracing Recommendations For Long-Span Concrete Girders," Florida, 2012.

[14] S. Timoshenko and J. Gere, Theory of Elastic Stability, $3^{a}$ edition. New York: McGraw-Hill, 1988.

[15] R. V. Southwell, "On the analysis of experimental observations in problems of elastic stability," Proc. R. Soc., vol. 135, pp. 601-616, 1932.

[16] P. Mandal and C. R. Calladine, "Lateral-torsional buckling of beams and the Southwell plot," Int. J. Mech. Sci., vol. 44, no. 12, pp. 2557-2571, 2002.

[17] J. B. Hurff, "Stability of Precast Prestressed Concrete Bridge Girders Considering Imperfections and Thermal Effects," Georgia Institute of Technology, 2010.

[18] M. C. V Lima and M. K. El Debs, "Numerical and experimental analysis of lateral stability in precast concrete beams," Mag. Concr. Res., vol. 10, pp. 635-647, 2005. 